\title{
Corporate Governance in Small and Medium Enterprises (SME) in India: Does Independent director make an impact on profits of SMEs
}

\author{
Mita Mehta ${ }^{1}$, Arti Chandani ${ }^{2}$, Ankita Bhatia ${ }^{3}$ \\ \{mita.mehta@sims.edu ${ }^{1}$, arti.chandani@sims.edu ${ }^{2}$,ankita.bhatia@sims.edu ${ }^{3}$ \} \\ Symbiosis Institute of Management Studies, Symbiosis International (Deemed University), Pune ${ }^{1,2,3}$
}

\begin{abstract}
This study is aimed to understand level of incorporation of Corporate Governance in Small and Medium Enterprises (SME) in India. The study review of literature aims at to bring out the level of incorporation of corporate governance in the SME of the developing countries. Though the sector is struggling to implement corporate governance, Reserve Bank of India has instructed the SMEs to implement better governance to have a better access to the finance from both the domestic and International financial institutions. In 2013, Security exchange board of India (SEBI) has allowed the listing of SMEs and the start-up companies in the SME without initial Public offering (IPO). Last few years have been quite progressive year for the SMEs as several policies interventions along with improved access to technology and innovation, are going to create a business friendly environment in the sector. The present study explores whether the presence of Independent director on the board does make a significant contribution to the profit of SMEs or SMEs using data for last 6 years for the SMEs listed in India.
\end{abstract}

Keywords: Corporate Governance, SME, Independent director, Profit after tax

\section{Introduction:}

Small and Medium Enterprises (SME) are a vital part of any emerging economy. When India is expected to be one of the biggest economies by 2025, SMEs form a vital backbone of any Economy. The advantages of the SMEs range from creating opportunities and encouraging entrepreneurship. The advancement of technology is opening new channels for the SMEs, which in turn creates a win-win situation to both the industry and the customers. One major disadvantage of this unorganized sector is the lack of proper corporate governance. Implementation of corporate governance (CG) is one of the best industry practices where there is transparency for all the stakeholders. The other advantages of incorporating CG in SMEs are better efficiency in management, saves the organization from insolvency, attract investors and most important of all prepare the company for initial public offering.

The SMEs is defined as "small and medium enterprises" (The definition given by the Small \& Medium Enterprises Development (MSMED) Act, 2006) defined MSME in a 2 category which is Manufacturing SME and (Investments made in plant and machinery) and Services SMEs (Investments made in Equipment). 


\begin{tabular}{|c|c|}
\hline \multicolumn{2}{|c|}{ Manufacturing SMEs - Investments made In Plant and Machinery } \\
\hline Type & INR \\
\hline Micro SMEs & Investments till Rs. 25Lacs \\
\hline Small SMEs & more than Rs. 25 Lacs to till Rs. 5 Cr \\
\hline Medium SMEs & more than Rs. 5 Cr to till Rs. 10 Crore \\
\hline \multicolumn{2}{|c|}{ Service SMEs - Investments made in Equipment } \\
\hline Type & INR \\
\hline Micro SMEs & Investments till Rs. 10Lacs \\
\hline Small SMEs & more than Rs. 10 Lacs to till Rs. $2 \mathrm{Cr}$ \\
\hline Medium SMEs & more than Rs. 2 Cr to till Rs. 5 Cr \\
\hline
\end{tabular}

Table 1 (Source: smechamberofindia.com)

\section{SME Evolution in India}

After the 3rd Five year plan Indian government focused on Industrialization and given importance to protect the Small scale industries (SMEs) The Karve Committee Report in the year 1955 given some guidelines to protect the SMEs by providing exclusive manufacturing rights for SME sector.

In the month of April 2015 Government of India has removed last 20 items which are reserved for production only through MSME. The reason behind this is to attract the foreign investment, increase the competition on international level, incorporating the better technologies etc.

\section{Current Overview of Indian SMEs}

Currently in India the SME sector consist 36 million units and it is providing employment to 80 million people. The sector has more than 6000 product portfolio and the sector contributing $8 \%$ of GDP of India in this it consist $45 \%$ of the hole manufacturing production and the $40 \%$ it exported from India to outside India. The Indian SME sector having a potential to contribute more to the GDP and overall economic and industrial growth of the country. SMEs also provides large employment opportunities in a country with lower capital cost as compare to large companies.

The biggest advantage of the SMEs that they are spread across the countries in smaller towns and rural areas therefore it will create the employment opportunities for lower sections of the people in a country so it will help the country to archive the inclusive growth of a nation. Growth of the SMEs also creates or provides the opportunities for new age entrepreneurs.

Under the guidelines of RBI (Reserve bank of India) there are national level, state level and district \& regional level institute who can provide finance to SMEs. These institute include banks, National small Industries commission, National Bank for Agriculture and Rural Development (NABARD), Small industries development bank of India (SIDBI), cooperative banks, state finance cooperation, regional rural banks etc. The problem of getting finance by SMEs is still unresolved despite of all these institutions. It is not only that SMEs are facing 
challenges with regard to finance but also other challenges such as market risk, competition from global players, availability of skilled manpower, non-availability of newer technologies etc.

The online business portal Firstbiz which is a part of India's biggest online news portal First post conducted a survey of India SMEs in the year 2014-15. The purpose of this survey was to find out the challenges faced by Indian SMEs.

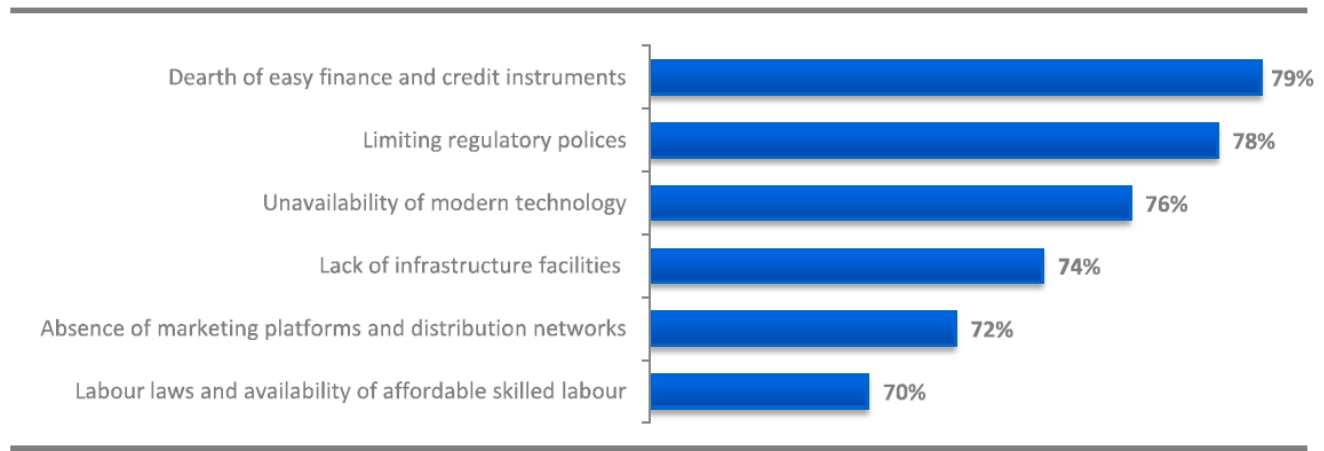

Source: FirstBiz-Greyhound Knowledge Group SME Survey 2014 ( $n=540$ )

Figure 1: Challenges faced by SMEs in India

The above figure shows the importance of finance and credit availability for SMEs where $79 \%$ of SMEs are facing this while regulatory policies are another major concern for the overall growth of the SMEs. These are the major which are to be addressed at the policy level to make a conducive environment for the SMEs to operate and flourish in India.

\section{Corporate Governance}

Corporate governance is a set of Rules, regulations, procedures and policies through which a company is protected and controlled by its management. Corporate governance mainly involve the balancing or protecting interest of its stakeholders which includes management or board members of the company, shareholders, customers, vendors, partners, lenders and concerned government bodies etc.

Corporate governance provides a proper framework and guidelines to the companies to achieve their desired objectives and it helps the companies for its internal control system, performance measurement and disclosure. Growth is not the only number which is being upon as the ultimate target for the companies but to have a good corporate governance in line which includes timely disclosures, CSR (Corporate Social Responsibility) initiative and society environmental awareness and transparent management practices is what desired.

"Corporate Governance is enhancing shareholders value in a company along with the equal and fair treatment to all its Investors, stakeholders, customers, employees, vendors and the society", Mr. Narayan Murhty 


\section{Evolution of Corporate Governance in India}

Lack of governance and transparency resulted for Asian crisis and this created an alarming situation not only for those economies but also for India. This also helped companies to understand importance and implementation of corporate governance in Indian corporate world. In India majority of the companies are family owned business such businesses have a biased attitude towards the non-family members of the company and hence the ownership is with them they may manipulate the things for their personal gain which are unethical in the eyes of law.

The companies act 2013 has tried to address this situation has made certain guidelines and policies for corporate governance and accounting system. After the liberalization various types of changes in the context of Financial Markets has been made in this process on of the major development was an establishment of Security Exchange Board of India (SEBI) in 1992.SEBI has played an important role for developing the corporate governance norms for the listed companies in India.

The first corporate Governance framework was created by Confederation of Indian industry (CII) under the guidance of Mr. Rahul Bajaj where team has made a several recommendations related to the Composition of a board, role of Directors, audit committee etc. This team submitted its recommendations in 1998.

In the year 1999, SEBI has appointed a committee under leadership of Mr. Kumarmangalam Birla for providing the better recommendations for listing agreements of the companies with the stock exchanges which will improve the existing corporate governance of the listed companies. The said committee made various crucial recommendations like timely disclosures, transparency in company activities and business transactions, accountability, equal treatment to all stakeholders, investors 'protection of investors rights etc. All these guidelines created in a code of governance and the same has been accepted by SEBI in the year 2000 and incorporated in a new Clause 49 Listing agreement.

SEBI has appointed various committees from time to time to study the need of corporate governance in India and these committees were headed by industrialist who gave their report on the various fronts to make Indian corporates transparent by instilling corporate governance practices being followed across globe. These recommendations include shareholders rights, stakeholders information, disclosure and transparency, composition of board including independent directors, non-executive directors, whistle blowing policy, audit committee, related party transactions and various other disclosures aimed to bring transparency in the actions of the board and management.

\section{Literature Review}

Structure of management and succession plan of the enterprise, welfare of the Stakeholders, Compliance to legal aspects of the business, Mission statement and policy statement are some of the key things which should be included in the practices by SMEs Dube et al (2011). Large firms have incorporate corporate governance while small firms lack in governance and competency. The SMEs can acquire knowledge through vendor, services, markets and collaboration. Formation of cluster based or technology exchanges can improve the governance aspects of small firms in India Banerjee Parthasarathi (2005). Majority of the SMEs studied did 
not have a board committee, while some SMEs did not have an idea about what a board committee was and very few SMEs had external director as researched by David (2015).

Public sector companies have started incorporating corporate governance practices post ninth plan in Malaysia while SMEs are having family members as their majority shareholders which gives them an edge over the minor stakeholder which manifest non-implementation of corporate governance code to regulated SMEs and their ownership (Amir et al, 2015).

Most of the SMEs had meeting which were semi-annually and annually. Commercial banks did not consider corporate governance as the criteria for granting credit in a study dons in SMEs in Ghana by David (2015). The companies did not adhere to corporate governance practices in Ghana and it did not have any impact to availability to the credit for the business.

Mahmood Shahnawaz in their study "Corporate Governance and Business Ethics for SMEs in Developing countries: Challenges and Way Forward" analyzed the challenges faced by SMEs in developing countries. The Main challenges faced by the SMEs are access to domestic and international capitals, increase in globalization, Changing Entrepreneurial cultures and dynamic Business Environment. The implementation of Corporate Governance will ease the processes of transparency, accountability and disclosure of timely material information. And it was found by the researchers that there was a lack of awareness among the enterprises about the significance of implementing corporate governance. The study gives a framework of implementation of corporate governance and steps to incorporate the same in the SMEs. The study is concluded by suggesting that the Government should provide better access to the firms which implement corporate governance and also the venture capital firms to provide encourage Entrepreneurs to impart a regulatory environment. In order to protect the investors, the developing countries are suggested to reform their legal and judicial system. The study is concluded by recommending that the SMEs to meet regularly with the Banks, Stock Markets and all financial institutions which work with the SMEs in order to give them an insight about the advantages of having an efficient corporate governance code and remove the notion of costs related the implementation of Corporate Governance. Audit firms also play a vital role in Costs related to SMEs.

Dube et al (2011) in their study "Corporate Norm in SME" analysed the possibility of implementing corporate governance in the SME sector and also give feasible solutions to the sector based on the possible findings. The Study emphasized on the changes of the world economy which paved the way for globalization and liberalization which in turn led to the development of Small and Medium Sized Enterprises. After conducting an empirical study, It was concluded that implementation of corporate strategy in SME sector depends on the Business in which each company is involved. Corporate governance should be more of a voluntary implementation and this sector need not be forced to new regulations but the sector to be informed and an awareness have to be created about the futuristic benefits of implementing corporate governance. The researchers are suggesting the financial institutions to extend financial support those SME who have incorporated corporate governance norms. This will encourage and act as a catalyst to implement such norms.

\section{Independent Director}

An independent director is a member of board of directors, who doesn't own any material in the company or any relationship with related persons, except sitting fees. There are different legal 
standards which are required to be fulfilled for having independent directors in the company. Moreover, these requirements vary from country to country. For instance, NYSE states that "no director qualifies as an 'independent' unless board of directors determines that the director has no material relationship with that of the company, either directly or as a partner." Similarly, in India, the expression 'independent directors,' means that a majority of the minimum directors of public companies should have a share capital in excess of Rs 100 million. These different rules of having independent directors across countries lead to inconsistent rules, in particular on the effect of director shareholding (Clarke, 2007).

The role of independent director's act as a guide to the company. One of the prominent roles broadly include risk management and thereby its impact on the net profit of the company. They also help in improvising the goodwill of the company and their corporate credibility. The independent directors also have an impact on the financial performance of the company. According to (Dalton et al.,) the size of the board of directors have a close association with the financial performance of the company.

According to (Maug, 1997) if independent directors fail to exercise control over management properly, takeovers could be the second best alternative. It has always been presumed that a monitoring board, if comprises of majority of independent directors is an important indicator of good corporate governance. Moreover, there is no strong evidence that firms with more independent directors perform better than other firms (Bhagat and Black, 2002).

In contrast, it has also been argued by many academicians and researchers that there is no significant correlation between independent directors and firms net profit. According to (Christensen et al.,) for Australian companies, it has been evidently observed that having more independent guidelines have a negative impact on ROA (Return on Assets) and company performance. Based on the case study of listed companies in Taiwan the operational performance of company has a positive correlation.

\section{Research Gaps}

Based on literature review which has been collected and analysed using resources such as SCOPUS, Emerald, and not many studies have focussed on corporate governance in SMEs in India. There are few studies which have been done and those are corporate governance in SME service firm, corporate governance norm for SMEs and competence of SMEs in India.

The research is gap has been identified as, corporate governance with respect to independent director and profit after tax in SMEs listed in India.

\section{Research Methodology}

The present study is quantitative and exploratory in nature where the researchers are trying to explore and find the relation between the corporate governance and performance of SMEs in India. The study is quantitative in nature as major tool for finding the relation is profit after tax which is numeric data of those SMEs. 


\section{Sample:}

The present study is conducted for all the SMEs which are listed in India on BSE and the list contains of 231 companies. . There were 5 companies whose data was not found therefore these companies have been removed from the data set which leaves researchers with 226 companies. These companies constitute the population as well as sample of SMEs listed in BSE.

\section{Period of Study:}

The researchers have used data of financial year 2012-13 to financial year 2017-18

\section{Source of Data:}

The data has been collected from various online and offline sources. The primary source of data is CMIE-Prowess from where researchers have collected data related to profit after tax and independent directors. The other sources of data include various journals, websites, reports etc.

\section{Statistical Tools:}

The researchers have used statistical tools such as correlation, mean, and standard deviation to study the variable and find the relations. SPSS 22 was used as the software to calculate these statistical measures.

\section{Objectives:}

The present study has been carried out with an objective to examine corporate governance in SMEs in India where role of independent director is being examined along with its impact on the reported net profit of the company. The specific objectives of the study are:-

1. To study corporate governance and its implication on SMEs listed in India

2. To find the relation between independent directors and profit and tax for SMEs listed in India

3. To suggest suitable measures based on findings of the analysis

\section{Hypothesis}

Ho: There is no relation between profit of the SMEs and number of Independent directors in the company.

Hi: There is no relation between profit of the SMEs and number of Independent directors in the company

\section{Data Analysis}

The researchers have studied all the SMEs which are listed on BSE and collected data on these SMEs using CMIE-Prowess. The time period of the study is 2012-13 to 2017-18 covering 6 financial years in total. There are certain companies for which information was missing for few years. Based on the data and analysis it is seen that there is a gradual increase in the adoption of corporate governance practices among the SMEs with the passage of times. The number of companies which had independent director in the financial year 2012-13 were very limited, while in the financial year 2017-18 there were 212 SMEs which has independent director. 
Bombay Stock has established BSE SME Platform as per the guidelines, rules and regulations provided by the SEBI. The main aim for creating a SME platform is to provide help for listing SMEs on BSE from unorganised sector to organised sector. The BSE SME platform opens the doors for listed SMEs to access the world of finance for their Future growth and Development.

Growth in SME sector has been much higher than average industrial growth in many countries (Raja et. al 2008). Number of SMEs have resorted to increase in their capital testifying that these SMEs are able to generate profits and into the business which is sustainable over long period. More than $85 \%$ of the SMEs are actively involved in the productions processes (Dube et al, 2011). In order to have sustainable SMEs sector, it is very important that these SMEs have access to financially sub sized promotion (Pandya, 2012).

The reported profit after tax has been taken as dependent variable to study the impact of presence of independent director which is independent variable and financial performance of SMEs.

\begin{tabular}{|rl|r|r|}
\hline \multicolumn{2}{|c|}{ Correlations } \\
\hline ID_2013 & Pearson Correlation & 1 & $.274^{* *}$ \\
& Sig. (2-tailed) & & .001 \\
& $\mathrm{~N}$ & 226 & 143 \\
\hline PAT_2013 & Pearson Correlation & $.274^{* *}$ & 1 \\
& Sig. (2-tailed) & .001 & \\
& $\mathrm{~N}$ & 143 & 143 \\
\hline
\end{tabular}

**. Correlation is significant at the 0.01 level (2-tailed).

Figure 2: Correlation between Profit after tax \& Independent Director, financial year 2012-13

There were 226 companies which were analysed while only 143 were found to have data pertaining to reported net profit and independent directors. The relation between profit and independent director has been found to be significant as per figure 2 . The significant value is less than 0.05 which also signifies that the correlation is significant. 


\section{Correlations}

\begin{tabular}{|ll|r|r|}
\hline & & ID_2014 & PAT_2014 \\
\hline ID_2014 & Pearson Correlation & 1 & .115 \\
& Sig. (2-tailed) & & .127 \\
& $\mathrm{~N}$ & 226 & 177 \\
\hline PAT_2014 & Pearson Correlation & .115 & 1 \\
& Sig. (2-tailed) & .127 & \\
& $\mathrm{~N}$ & 177 & 177 \\
\hline
\end{tabular}

Figure 3: Correlation between Profit after tax \& Independent Director, financial year 2013-14 Looking at the correlation table as given in figure 3 , it is interpreted that the correlation is not significant between reported profit after tax and number of independent directors. There are 226 companies as the sample while only 177 SMEs has independent directors and 49 SMEs did not have independent directors. Only 1 SMEs had 4 independent director. The significant value is .127 which is more than 0.05 , signifying insignificant relation between independent director and reported net profit.

\begin{tabular}{|ll|r|r|}
\hline \multicolumn{2}{|c|}{ Correlations } \\
\hline ID_2015 & Pearson Correlation & 1 & -.050 \\
& Sig. (2-tailed) & & .483 \\
& N & 2015 & PAT_2015 \\
& Pearson Correlation & -.050 & 195 \\
\hline PAT_2015 & .483 & 1 \\
& Sig. (2-tailed) & 195 & 195 \\
& N &
\end{tabular}

Figure 4: Correlation between Profit after tax \& Independent Director, financial year 2014-15

The relation between independent director and profit after tax is not found to be significant for the financial year 2014-15 as shown in figure 4. The number of companies having independent director are more in comparison to previous years. There were few companies which had 5 or 6 independent directors and all this is the result of enactment of Companies act, 2013. 


\begin{tabular}{|ll|r|r|}
\hline \multicolumn{2}{|c|}{ Correlations } \\
\hline ID_2016 & Pearson Correlation & 1 & $-.186^{* *}$ \\
& Sig. (2-tailed) & & .007 \\
& $\mathrm{~N}$ & 226 & 207 \\
\hline PAT_2016 & Pearson Correlation & $-.186^{* *}$ & 1 \\
& Sig. (2-tailed) & .007 & \\
& $\mathrm{~N}$ & 207 & 207 \\
\hline
\end{tabular}

**. Correlation is significant at the 0.01 level (2-tailed).

Figure 5: Correlation between Profit after tax \& Independent Director, financial year 2015-16

The data pertaining to financial year 2015-16 is showing significant correlation between independent directors and profit after tax as given in figure 5. The number of SMEs having independent directors are 207 which is more than what it was in the financial year 2014-15. The significant value is much more than 0.05 which means the relation between independent director and reported net profit is significant.

\begin{tabular}{|rl|r|r|}
\hline \multicolumn{4}{|c|}{ Correlations } \\
\hline ID_2017 & ID_2017 & PAT_2017 \\
& Pearson Correlation & 1 & -.131 \\
& Sig. (2-tailed) & & .055 \\
& $\mathrm{~N}$ & 226 & 216 \\
\hline PAT_2017 & Pearson Correlation & -.131 & 1 \\
& Sig. (2-tailed) & .055 & \\
N & 216 & 216 \\
\hline
\end{tabular}

Figure 6: Correlation between Profit after tax \& Independent Director, financial year 2016-17 


\section{Correlations}

\begin{tabular}{|ll|r|r|}
\hline & & ID_2018 & PAT_2018 \\
\hline ID_2018 & Pearson Correlation & 1 & -.042 \\
& Sig. (2-tailed) & & .546 \\
& $\mathrm{~N}$ & 226 & 212 \\
\hline PAT_2018 & Pearson Correlation & -.042 & 1 \\
& Sig. (2-tailed) & .546 & \\
& $\mathrm{~N}$ & 212 & 212 \\
\hline
\end{tabular}

Figure 7: Correlation between Profit after tax \& Independent Director, financial year 2017-18

The relation between profit after tax and independent director is not found to be significant for financial year 2016-17 and 2017-18. On observation, it has been found that the number of independent directors have increased and in the 2017-18 the maximum number of independent directors were 7 , which were highest among all.

\begin{tabular}{|c|c|c|c|c|c|c|}
\hline & $\mathbf{2 0 1 2 - 1 3}$ & $\mathbf{2 0 1 3 - 1 4}$ & $\mathbf{2 0 1 4 - 1 5}$ & $\mathbf{2 0 1 5 - 1 6}$ & $\mathbf{2 0 1 6 - 1 7}$ & $\mathbf{2 0 1 7 - 1 8}$ \\
\hline Mean & 5.4371 & 5.122 & 6.34 & 7.02 & 11.17 & 18.16 \\
\hline Minimum & -90.50 & -90.20 & -68.50 & -143.60 & -150.20 & -207.70 \\
\hline Maximum & 119.80 & 158.80 & 149.70 & 158.60 & 277.40 & 429.00 \\
\hline Stand. Deviation & 16.97 & 18.43 & 16.49 & 20.70 & 29.16 & 44.87 \\
\hline
\end{tabular}

Table 1: Summary statistics- Profit After Tax

The researchers have analysed profit after tax for 6 financial years and the summary statistics is presented in table 1. Mean profit after tax has increased from Rs. 5.4371 (million) to Rs. 18.16 (million) in 2017-18. There has been a continuous growth in the profit after tax during the period of study where maximum profit has increased from Rs. 119.80 (million) to Rs. 429.0 (million) in 2017-18 and there is an increase in the minimum profit (loss) for the same period and reported loss was Rs. 207.70 (million) in 2017-18. The standard deviation of profit has also increased from 16.97 to 44.87 signifying the wide spread of profit for the SMEs in India.

\begin{tabular}{|c|c|c|c|c|c|c|}
\hline & $\mathbf{2 0 1 2 - 1 3}$ & $\mathbf{2 0 1 3 - 1 4}$ & $\mathbf{2 0 1 4 - 1 5}$ & $\mathbf{2 0 1 5 - 1 6}$ & $\mathbf{2 0 1 6 - 1 7}$ & $\mathbf{2 0 1 7 - 1 8}$ \\
\hline Mean & 0.1239 & .3407 & 0.6726 & 1.11 & 1.50 & 2.46 \\
\hline Minimum & 0 & 0 & 0 & 0 & 0 & 0 \\
\hline Maximum & 4 & 5 & 6 & 6 & 4 & 7 \\
\hline $\begin{array}{c}\text { Standard } \\
\text { Deviation }\end{array}$ & 0.590 & 0.9398 & 1.30 & 1.46 & 1.42 & 1.27 \\
\hline
\end{tabular}

Table 2: Summary statistics- Independent Directors 
Independent directors were not present in many SMEs in the year 2012-13 and the same situation continued till 2017-18 while the number of companies decreased where independent directors were nil. The table also shows the maximum number of independent directors were 4 in 2012-13 while maximum number of directors were 7 in financial year 2017-18. The standard deviation moved from 0.590 to 1.27 . The summary statistics as given in table 2 is of prime importance to all the stakeholders.

\section{Conclusion and Recommendations}

From the above review of Literatures related to Small and Medium Enterprises, it can be concluded that the SMEs play a vital role in the contribution of the GDP, employment generation and contribute to the economies of the developing countries. Most of the SMEs still lag behind in access to credit and capital from domestic and International Financial Institutions. This is due to the lack of awareness among the enterprises regarding corporate governance. A strong corporate governance framework would result in the transparency, improved business environment and protection of the investors. It can also be inferred that the incorporating corporate governance not only requires a strong legal framework but also personal commitment from the enterprise. Firm performance has been positively affects with the implementation of corporate governance practices (Raja, 2008). Poor managerial know how, poor governance are the factors which contribute to the decrease in competitiveness (Banerjee, June, 2005).

The relations between independent directors and profit after tax was analysed for the period of study. The relation was found to be significant only for two financial years viz. 2012-13 and 2015-16 while for the remaining years the relationship was not found to be significant while leads to the rejection of hypothesis. Looking at the summary statistics of profit after tax it is also seen that there has been a gradual increase in the profit of SMEs during period of study. Not only profit of the SMEs has increased but the loss of the SMEs has also increase over time. There has been an increase number of independent directors on SMEs. The number of companies have zero independent director decreased from 2012-13 to 2017-18 and at the same time, the number of independent directors increased in those SMEs.

Based on the Study, the following recommendations for good corporate governance practices in SMEs are:

- $\quad$ Timely reporting/Disclosures to Domestic and Foreign investors

- Formation of Committees which actively monitors functioning and remunerations of the board members.

- A secure system to prevent whistleblowers

- Identification of potential risks and forecasting them in every six months.

- Enterprises to be subjected to regular time bound inspections / investigation by governing bodies

Though there is no single approach to corporate governance that would match all the requirements of all the industries altogether, the norms change based on the business requirements. Good Corporate Practices will have a higher impact in the Market value of the 
enterprise which will increase the investments substantially rather than short term benefits like improved operational efficiency. The regulator should formulate corporate governance practices for SMEs (Sheila et. al, 2013). Corporate governance brings new strategic outlook with the help of external independent directors in the case of SMEs in Ghana (Josuha, 2007). Lastly, to include a good corporate governance practice involves transparency in decision making and making the information public. Rather than an efficient Legal framework it requires an urge and commitment which is deep rooted in the organization to incorporate corporate governance practices.

\section{References}

[1]Abor, J., \& Adjasi, C. K. (2007). Corporate governance and the small and medium enterprises sector: theory and implications. Corporate Governance: The international journal of business in society, 7(2), 111-122.

[2]Banerjee, P. (2005). Corporate Governance and Competence in SME's in India. CACCI Journal, 1(1), 1-13.

[3]Bhagat, S., \& Black, B. (2002). The non-correlation between board independence and long-term firm performance. J. CorP. 1., 27, 231.

[4]Clarke, D. C. (2007). Three concepts of the independent director. Del. J. Corp. L., 32, 73. [5]Christensen, J., Kent, P., \& Stewart, J. (2010). Corporate governance and company performance in Australia. Australian Accounting Review, 20(4), 372-386.

[6]Dalton, D. R., Daily, C. M., Johnson, J. L., \& Ellstrand, A. E. (1999). Number of directors and financial performance: A meta-analysis. Academy of Management journal, 42(6), 674686.

[7]Dube, I., Dube, D., \& Mishra, P. (2011). Corporate governance norm for SME. Journal of Public Administration and Governance, 77-123.

[8]Dzigba, D. (2015). Corporate Governance Practice among Small and Medium Scale Enterprises (SMEs) in Ghana; Impact on Access to Credit.

[9]Htay, S. N. N., \& Salman, S. A. (2013). Corporate governance: A case study of SMEs in Malaysia. Middle-East Journal of Scientific Research, 18(2), 243-252.

[10]Mahmood, S. (2008, July). Corporate governance and business ethics for SMEs in developing countries: Challenges and way forward. In International Society of Business, Economics, and Ethics World Congress (pp. 15-18).

[11]Maug, E. (1997). Boards of directors and capital structure: alternative forms of corporate restructuring. Journal of Corporate Finance, 3(2), 113-139.

[12]Pandya, V. M. (2012, September). Comparative analysis of development of SMEs in developed and developing countries. In The 2012 International Conference on Business and Management (pp. 6-7).

[13]Raja, J., \& Kumar, A. S. (2007). SME entrepreneurship, firm performance, and corporate governance practices in Indian service firms. Journal of Services Research, 7(2), 99.

[14]SHREEMALI, J., \& SHRIMALI, D. H. A Study of Corporate Governance Practices in Companies Across Countries with a view to Identify Measures for Good Corporate Governance In India.

[15]Umrani, A. I., Johl, S. K., \& Ibrahim, M. Y. (2015). Corporate Governance Practices and Problems Faced by SMEs in Malaysia. Global Business \& Management Research, 7(2). 
https://economictimes.indiatimes.com/small-biz/policy-trends/need-to-implement-smescorporate-governance-code-rbi/articleshow/12641597.cms?from $=$ mdr ( accessed on 25th June, 2019)

https://economictimes.indiatimes.com/small-biz/sme-sector/indian-sme-trends-the-yeargone-by-and-2017/articleshow/56254240.cms?from $=\operatorname{mdr}($ accessed on 24th June,2019) 